Research Journal of Applied Sciences, Engineering and Technology 5(9): 2765-2770, 2013

DOI:10.19026/rjaset.5.4804

ISSN: 2040-7459; e-ISSN: 2040-7467

(C) 2013 Maxwell Scientific Publication Corp.

Submitted: September 27, $2012 \quad$ Accepted: November 11, $2012 \quad$ Published: March 20, 2013

\title{
Research Article \\ A Review on Technologies and Methods of Mitigating Impacts of Large-Scale Intermittent Renewable Generations on Power System
}

\author{
Yujiao Liu and Chuanwen Jiang \\ Department of Electrical Engineering, Shanghai Jiao Tong University, \\ Dongchuan Road 800, Shanghai, 200240, China
}

\begin{abstract}
With environmental pressure and the development of smart grid, penetration of large-scale renewable energy to power system seems to be imperative. However, it encounters some obstacles because of intermittencies of Renewable Generations (RGs). So mitigating impacts of intermittent RGs is a key issue for development of power system and this study presents a review on recent researches referring the problem from both electrical technologies and human factors. Technologies of storage, advance automation, electric vehicles, demand side management, risk constraint power system management, policies of renewable energies and the future research directions of them were discussed by the bibliographical survey.
\end{abstract}

Keywords: Demand side management, electric vehicle, power system operation, renewable generation, risk management, storage

\section{INTRODUCTION}

Conflicts between energy consumption demands of economic development and lower emission demands of environment have dramatic intensified in recent years. Renewable energies are the first choices of most countries to alleviate the above contradiction. Renewable energies are the first choices of most country to alleviate the above contradiction. Methods of utilizing renewable energies could be divided into two categories: the first one was to directly convert them into electricity or thermal energies and the other one is to convert them into energies which could be solved easily, such as chemical energy (Lewis and Nocera, 2007; Mohseni et al., 2012). To convert those renewable energies into electricity energies is the best choice for large-scale utilization of them, for electricity is an excellent secondary energy which have already been utilized extensively and transported easily.

Currently, exploitation of renewable energies by power system could not reach an ideal degree. This is because power system must keep power balance in any time to insure power supply and power equality and currently method to keep this balance is to adjust outputs of generations to satisfy the changing demands by multi-time step operations for adjustments of traditional thermal units needs times, which means power system must have enough control and adjusting abilities of those generations with any time scales form intra-hourly, intra-daily and daily, to monthly and yearly time scales. However, RGs would affect the balance and operations of power systems because outputs of RGs of all time scales are with intermittent and some extent uncontrollable and unpredictable characteristics, especially for wind and photovoltaic generations which are the mainly renewable energies utilized by power grids. Those characteristics have contradictions with the demands of control abilities of power grids, which would affect the reliabilities of power system. Details of intermittent and fluctuation of RGs and their impacts are as follow.

Daily or longer time fluctuation of renewable energy could be evaluated by mean power density of different time ranges, which decided the outputs of renewable generations of the corresponding times. Study of Akpinar and Akpinar (2005), Ouammi et al. (2010) and Karakoti et al. (2012) analyzed the seasonal and monthly mean values of power density of wind and solar energy based on several years' data of wind speeds and solar diffuse irradiations. From those literatures, the maximum seasonal and monthly mean power density of renewable energies would be several times more than the minimum ones and some regions have the lower wind power density in summer or winner, which would have larger loads in most areas. Similar situations happen in daily time scale. Maximum mean hourly power densities of wind and solar energy often have differences of several times with the

\footnotetext{
Corresponding Author: Chuanwen Jiang, Department of Electrical Engineering, Shanghai Jiao Tong University, Dongchuan Road 800, Shanghai 200240, China

This work is licensed under a Creative Commons Attribution 4.0 International License (URL: http://creativecommons.org/licenses/by/4.0/).
} 
minimum ones of the same day. Specially, mean hourly wind speeds often reach peak point in night while reach bottom at noon, while outputs of photovoltaic generations reach the largest value at noon and zero in night. So from the view of daily or longer scales, renewable generations have uncertainty load carrying abilities, especially for wind energy which often has low ability while demands were large and high ability while demands were small. In addition, power system needs a forecasting of outputs of RGs for operations since RGs could not be totally control. Therefore, beyond the self-fluctuations of renewable generation, forecasting errors of outputs of renewable generations were also fluctuations for power system.

The uncertain load carrying abilities brings difficulties to both long time planning and short time scheduling of power system. Power system needs enough install capacity of generations to sever the demands of the future years and enough reserves to follow the demands during the day or longer. However, system might face power shortage, generation efficiency and extra reliability costs problems if the plan was made based on expectations and predictions of outputs of renewable generations (Ummels et al., 2007; Holttinen, 2005), for outputs of RGs would not always reach expectations and follow predictions, which equalizes to increases of load fluctuations and expectations.

Set views on shorter time scales, intra-hourly fluctuations of RGs have impacts on regulation and load following of power system (Makarov et al., 2008) and minute-to-minute variations need the remaining conventional power plants to provide not only sufficient rotational energy and reserves but also adequate control abilities to keep an acceptable dynamic state of power system, otherwise the variations of RGs would make outrage variations of system frequency (Banakar et al., 2008). For more information, although variation of RGs from the rated power to zero within minutely time is with small probability, those extremes still limited the penetration of RGs (Luo et al., 2007). Minutely oscillations also effects voltage and transient stability of power system (Meegahapola and Flynn, 2010).

In general, uncertainty load carrying abilities have impacts on reliability of power supply which was decided by expectation planning and short time operating of power system, while variations of renewable generations in minutely and intra-hourly scale have impacts on transient stability and power quality which was decided by real time management of power system. However, forced by environmental pressures, power system had to use these renewable energy sources and it truly happens which could be proved by the rapidly increasing penetrations of RGs in recent years. Thence researches to suppress impacts of RGs are important and necessary to ensure reliability of power system integrated with intermittent renewable energy source. And this study attempted to present a literature review of them.

\section{TECHNOLOGIES OF MITIGATING IMPACTS OF RGs}

As introduced in above section, reasons of disadvantage impacts of renewable energies are the contradiction of variations of RGs' outputs and adjusting abilities of power systems, so to mitigate the impacts could start from aspects of reducing variations of RGs and enhance adjusting abilities of power grids.

Energy storage components: Although to storage large amounts of energies, such as energies of hourly outputs of all RGs in a power system and then utilize them whenever needed is still impossible with current technology, to reduce the volatility of RGs with fast response energy storage components is now entirely feasible. Study of Abbey and Joos (2007) utilized super capacitor to improve performances of wind turbines, in which the simulation results showed that the added energy storage system could stabilize short time power fluctuations and transient voltage and frequency in some extent and the improvement was depended by storage capacity. Study of Ye and Sun (2009) combined micro flywheels and photovoltaic generations to adjust the original daily outputs of photovoltaic generations to load-suitable ones. So small capacity storage components could directly change transient performances of RGs by reducing minutely power fluctuations, which equalized blocking them from power grid in some degree.

With response time of about ten minutes and rated power of hundreds of megawatts, pumped storage is the most used technology of large-scale applications in power system to solve hourly and daily fluctuations of RGs and loads (Schainker, 2004). However, pumped hydro was limited to terrain conditions. Fast response middle scale storage technologies of flywheel, compress air, battery and superconducting magnetic have made great improvements in recent years, which provide the probability of directly using of them by power system. Compress air technology could satisfy the short time flexible requirement of high wind penetrated power system (Swider, 2007), in which the authors concluded that compress air facilities have both technology and economic driving forces in electricity markets with RGs. Battery storages response in second time scale and with rated power and capacities from $100 \mathrm{~W}$ and $1 \mathrm{KWh}$ to about $100 \mathrm{MW}$ and $200 \mathrm{MWh}$, respectively (Guerrero et al., 2009), which are helpful for power quality, transient stability, load following and daily scheduling (Doughty et al., 2010). Superconducting magnetic technologies are also with rapid response and large power and energy density (Molina et al., 2011), which would be very suitable for power system to reduce impacts of RGs if costs of them were lower. 
Over all, storage facilities could directly reduce or countervail fluctuations of outputs of RGs with their energy storage and fast response functions. Yet, since different types energy storage appliances are with different characteristics and costs, power system and RGs need to choose energy storage facilities with appropriate type and capacity. Combining different energy storage technologies would be a good choices from both economic and technology views for variations and forecasting errors of RGs happens in all time scales and are with different levels. For more information, energy storage components need right management to make full plays and small capacity applications in RGs or power system are generally controlled by automation facilities while grid-scale storages are co-managed with generations by power system.

Advanced automation facilities: Advanced control technologies and rapid compensation facilities of power systems have got a great deal of progresses recently by the motivation of intermittent RGs. Dynamic performances of voltage control, frequency regulation, load following of systems with high penetrations of RGs could be improved a lot with technologies of Automatic Generation Control (AGC), frequency control and voltage control (Golpira et al., 2012; Abe et al., 2006). Flexible AC Transmission System (FACTS) devices also made great efforts to enhance the systems' adjusting abilities to mitigate impacts of RGs and had achieved lots of effects (Abe et al., 2006).

Beyond the above technologies which improved the response abilities of traditional generators and transmission systems, control and compensation technologies of RGs could also reduce their impacts on power system by improving performances of voltage and frequency, which could be achieved by offering methods for directly control of active and reactive power of RGs and corresponding compensation components (Morren et al., 2006; Zhang et al., 2012; Chowdhury et al., 2012).

For a short summary, advanced control facilities played roles of mitigating short time impacts of RGs on power system by rapid compensations on fluctuations of RGs though automatic managing fast response resources including AGC capacities, FACTS and energy storage components with presetting strategies.

Demand side management and electric vehicles: Demand side management was an effective method of reducing impacts of RGs, for one of its objectives was minimizing impacts of inadequate power supply by optimized shedding loads (Faranda et al., 2007), or by operations on interruptible loads (Pedrasa et al., 2009). However, the developments of controllable and rechargeable appliances, especially for electrical vehicles and micro grids with distributed generation, provide great demand response resources for demand side management, which would make demand side management pays a greater role than before.

Study of Kempton and Tomic (2005) proposed the supporting roles of technologies of vehicle-to-grid on penetration of large-scale renewable energies, in which the authors suggested that vehicles could play similar roles of spinning reserves to reduce impacts of RGs. Charging of electric vehicles also run in centralized model as battery switch stations. However, battery switch stations could give more supporting than vehicle-to-grid on penetration of RGs, for they have larger capacity of energy storage and lower stochastic (Takagi et al., 2010). Furthermore, battery switch stations could set up micro grids with RGs, like other micro grids consists of distributed generations and energy storage components, to directly isolate variations of RGs from main grids and offer reserves by participating in demand response (Shinji et al., 2008).

Generally, batteries of electric vehicles could play roles of energy storages for both vehicles and power grids and the future capacity of them would be tremendous comparing with other storage technology. So how to bring the enthusiasm of electric vehicles into real time power system operation is an important research direction for mitigating impacts of penetration of renewable energies on power system.

Short-term scheduling integrated with risk management: Penetration of RGs brings both economic and security impacts on power system. From view of scheduling time scale, to provide more spinning reserves and take more security constraints into short term operation model could reduce security impacts of RGs, but it would enhance economic impacts. In order to build a balance between reducing economic and security impacts, risk management methods have been introduced into short term scheduling.

Risk management of short term operation is an aggregate concept, which includes many criteria involved with system cost, power balance, voltage stability and other security or economic risks.

Study of Aminifar et al. (2009) proposed a unit commitment model with probabilistic spinning reserve constraints, Expected Energy Not Supplied (EENS) limits and consideration of interruptible loads. Combined the model with the management strategy of spinning reserves with RGs in Ortega-Vazquez and Kirschen (2007), it would have the ability of controlling impacts of RGs. In Lee (2007), the authors added the outrage cost into objective function of scheduling and utilized hourly EENS constraints to achieve the aim of controlling impacts of wind energy with lowest cost. By evaluating financial risk of short-term operation plans with value at risk method and making decisions with integrated risk management, the proposed scheduling model in ( $\mathrm{Li}$ and Jiang, 2011) offers a solution for controlling risks of wind penetration. 
For a concise summary, Models of reducing or control impacts of RGs by short-term scheduling combined with risk management evolved from the traditional ones by adding financial or security risk constraints into traditional model, or by adding financial risk terms in traditional objective functions of short-term scheduling and taking consideration of security risks by transferring them to financial losses. And in order to control and reduce impacts of largescale RGs, professional risk evaluation and control methods must be introduced to scheduling model of power system. Furthermore, the newly scheduling models should not only add professional risk evaluation and management method, but also take the emerging technologies into account, e.g., energy storage and demand response.

Long time planning with constraints of response abilities of all time scales: Energy and grid structures, which were mainly decided by long time planning, would be the decisive factors of response abilities and demands of RGs for all operations were limited by resources of generation and transmission facilities. So optimizing generation composition of power systems to offer enough response abilities for all time scales in long time planning is important for reducing impacts of RGs (Isaacs, 2008; Zhao et al., 2011; Lannoye et al., 2011). For more information, renewable energies could reduce intermittency by combination of themselves, especially for combination of wind and photovoltaic generations (Yang et al., 2003). Hence, long time planning model with consideration of large-scale RGs should take constraints of system response abilities into account in order to keep reliable power supply. Article (Ding and Somani, 2010) proposed a method of long time generation planning with the consideration of impacts of fluctuation of wind energy and it figured out that to develop associated energy storage systems to offer enough response abilities for large-scale wind energy was necessary based on current technologies of thermal unit. For the reason that rapidly controls capacities, grid scale energy storage, emission factors and stochastic programming have been all introduced into generation expansion planning model and solution methods (Kamalinia et al., 2011; Hu et al., 2011).

Comparing with traditional long time planning model of power system, the one with consideration of reducing impacts of large-scale RGs has more concerns on short time securities, which was present as the constraints of response abilities of different abilities.

Policies: Except all the above methods by power grids and consumers, government and related organizations also should make efforts on the issue.

RGs' performances have been improved a lot comparing with previous productions and are continuously improving, such as variable speed double feed wind turbines with advance control units have stronger control abilities of frequency and voltage (Mauricio et al., 2009), which had mentioned in subsection "Advanced Automation Facilities". So to enhance standards of grid-connected RGs, which forces RGs to follow the advanced technologies, is an effective way to reducing the above impacts. Grid connected standards should at least including the following factors: limited control abilities of active power outputs, basic power factor requirements, voltage control abilities and other factors achieved by currently technologies (Spooner and Harbidge, 2001; Nelson, 2011).

To totally avoid outrages in some extra situations of power system with high penetration of RGs would be impossible and as introduced in subsection "Short-term scheduling integrated with risk management", shedding loads to avoid black out would be the only choices in those situation. However, renewable energy insurance could reduce impacts of RGs on power system when outrages happened in some extra situations, because the insurance company would afford the compensations for outrage consumers. So except the above technologies standards, incentive polices on covering extra whether insurance of RGs would play an active role in reducing impacts of RGs.

\section{CONCLUSION}

To mitigate impacts of penetration of large-scale intermittent RGs on power system is a key issue of smart and green grid. This study aimed to make literature reviews on the problem from both of power electronic facility technologies and power system management methods. And from these studies, it could conclude from the following aspects:

- The impacts of RGs on power system depend on both penetration level of RGs and flexibility of power system of all time scales. So methods of restrain those impacts focused on reducing fluctuation of RGs and enhancing response abilities of power system.

- Energy storage and advance automation facilities, e.g., AGC and FACTS are the mainly research focuses from the view of power electric facilities, for they could make great contributions on frequency control and load following by their fast response ability. However, technologies to improve the primary frequency regulation abilities of thermal units are also merit attention.

- To offer enough response abilities of all time scales is the best method from the point reducing security impacts of RGs, however, it is economical unacceptable. So to balance security and economical impacts is the mainly task of power system management. Integrating risk constraints 
and risk management to traditional scheduling and planning model would be the only choice for managers and operators of power system.

- Because to satisfy demands of response abilities of different time scales needs different technologies, the longer time planning must take demands of shorter time scale into account. For example, long time planning must consider the demands of response abilities of short term scheduling and real time management.

- Progresses of technologies of RGs and corresponding financial services, e.g., insurances for renewable energy, would have directly promote on reducing impacts of them, so polices of encouraging owners of RGs to follow new technologies would also make contributions on the issue.

\section{REFERENCES}

Abe, K., S. Ohba and S. Iwamoto, 2006. New load frequency control method suitable for large penetration of wind power generations. Power Engineering Society General Meeting, 1-9: 3578-3583.

Abbey, C. and G. Joos, 2007. Supercapacitor energy storage for wind energy applications. IEEE Trans. Ind. Appl., 43: 769-776.

Akpinar, E.K. and S. Akpinar, 2005. An assessment on seasonal analysis of wind energy characteristics and wind turbine characteristics. Energ. Convers. Manage., 46: 1848-1867.

Aminifar, F., M. Fotuhi-Firuzabad and M. Shahidehpour, 2009. Unit commitment with probabilistic spinning reserve and interruptible load considerations. IEEE Trans. Power Syst., 24: 388-397.

Banakar, H., C. Luo and B.T. Ooi, 2008. Impacts of wind power minute-to-minute variations on power system operation. IEEE Trans. Power Syst., 23: 150-160.

Chowdhury, M.A., N. Hosseinzadeh and W.X. Shen, 2012. Smoothing wind power fluctuations by fuzzy logic pitch angle controller. Renew. Energ., 38: 224-233.

Ding, J. and A. Somani, 2010. A long-term investment planning model for mixed energy infrastructure integrated with renewable energy. IEEE Conference on Green Technologies, Grapevine, TX, pp: 1-10.

Doughty, D.H., P.C. Butler, A.A. Akhil, N.H. Clark and J.D. Boyes, 2010. Batteries for large-scale stationary electrical energy storage. Electrochem. Soc. Interf., 19: 49-53.

Faranda, R., A. Pievatolo and E. Tironi, 2007. Load shedding: A new proposal. IEEE Trans. Power Syst., 22: 2086-2093.

Golpira, H., H. Bevrani and A.H. Naghshbandy, 2012. An approach for coordinated automatic voltage regulator-power system stabiliser design in large- scale interconnected power systems considering wind power penetration. IET Gener. Transm. Distrib., 6(1): 39-49.

Guerrero, M. A., E. Romero, F. Barrero, M.I. Milanes and E. Gonzalez, 2009. Overview of medium scale energy storage systems. Procceding of the Compatibility and Power Electronics (CPE), Badajoz, pp: 93-100.

Holttinen, H., 2005. Impact of hourly wind power variations on the system operation in the Nordic countries. Wind Energ., 8: 197-218.

Hu, Q., G.H. Huang, Y.P. Cai and Y. Huang, 2011. Feasibility-based inexact fuzzy programming for electric power generation systems planning under dual uncertainties. Appl. Energ., 88: 4642-4654.

Isaacs, A.C., 2008. Electricity supply structures and governmental policy and their impact on the use of renewable energy in the caribbean. IEEE Power and Energy Society General Meeting, 1-11: 4835-4841.

Kamalinia, S., M. Shahidehpour and A. Khodaei, 2011. Security-constrained expansion planning of fastresponse units for wind integration. Electr. Pow. Syst. Res., 81: 107-116.

Karakoti, I., P.K. Das and S.K. Singh, 2012. Predicting monthly mean daily diffuse radiation for India. Appl. Energ., 91: 412-425.

Kempton, W. and J. Tomic, 2005. Vehicle-to-grid power implementation: From stabilizing the grid to supporting large-scale renewable energy. J. Power Sourc., 144: 280-294.

Lannoye, E., D. Flynn and M. O'malley, 2011. Society General Meeting, The role of power system flexibility in generation planning. IEEE Power and Energy Society General Meeting, San Diego, CA.

Lee, T.Y., 2007. Optimal spinning reserve for a windthermal power system using EIPSO. IEEE Trans. Power Syst., 22: 1612-1621.

Lewis, N.S. and D.G. Nocera, 2007. Powering the planet: Chemical challenges in solar energy utilization. Proceeding of the National Academy of Sciences of the United States of America, 104: 20142-20142.

Li, X.H. and C.W. Jiang, 2011. Short-term operation model and risk management for wind power penetrated system in electricity market. IEEE Trans. Power Syst., 26: 932-939.

Luo, C.L., H.G. Far, H. Banakar, P.K. Keting and B.T. Ooi, 2007. Estimation of wind penetration as limited by frequency deviation. IEEE Trans. Energ. Convers., 22: 783-791.

Makarov, Y.V., C. Loutan, J. Ma, P. de Mello and $\mathrm{S}$. $\mathrm{Lu}, 2008$. Impacts of wind generation on regulation and load following requirements in the California system. IEEE Power and Energy Society General Meeting-Conversion and Delivery of Electrical Energy in the 21st Century, Institute of Electrical and Electronics Engineers, Piscataway, NJ. pp: 1-9. 
Mauricio, J.M., A. Marano, A. Gomez-exposito and J.L.M. Ramos, 2009. Frequency regulation contribution through variable-speed wind energy conversion systems. IEEE Trans. Power Syst., 24: 173-180.

Meegahapola, L. and D. Flynn, 2010. Impact on transient and frequency stability for a power system at very high wind penetration. IEEE conference on Power and Energy Society General Meeting, Minneapolis, MN, pp: 1-8.

Mohseni, F., M. Magnusson, M. Gorling and P. Alvfors, 2012. Biogas from renewable electricity: Increasing a climate neutral fuel supply. Appl. Energ., 90: 11-16.

Molina, M.G., P.E. Mercado and W.E. Hirokazu, 2011. Improved Superconducting Magnetic Energy Storage (SMES) controller for high-power utility applications. IEEE Trans. Energ. Convers., 26: 444-456.

Morren, J., S.W.H. de Haan, W.L. Kling and J.A. Ferreira, 2006. Wind turbines emulating inertia and supporting primary frequency control. IEEE Trans. Power Syst., 21: 433-434.

Nelson, R.J., 2011. A review of existing standards for specifying wind turbine generator electrical performance: A 2010 year-end status report. IEEE Conference of Power and Energy Society General Meeting, San Diego, CA, pp: 1-4.

Ortega-Vazquez, M.A. and D.S. Kirschen, 2007. Optimizing the spinning reserve requirements using a cost/benefit analysis. IEEE Trans. Power Syst., 22: 24-33.

Ouammi, A., H. Dagdougui, R. Sacile and A. Mimet, 2010. Monthly and seasonal assessment of wind energy characteristics at four monitored locations in Liguria region (Italy). Renew. Sust. Energ. Rev., 14: 1959-1968.

Pedrasa, M.A.A., T.D. Spooner and I.F. Macgill, 2009. Scheduling of demand side resources using binary particle swarm optimization. IEEE Trans. Power Syst., 24: 1173-1181.
Schainker, R.B., 2004. Executive overview: Energy storage options for a sustainable energy future. IEEE Power Engineering Society General Meeting, 1-2: 2309-2314.

Shinji, T., T. Sekine, A. Akisawa, T. Kashiwagi, G. Fujita and M. Matsubara, 2008. Reduction of power fluctuation by distributed generation in micro grid. Electr. Eng. Japan, 163: 22-29.

Spooner, E.D. and G. Harbidge, 2001. Review of international standards for grid connected photovoltaic systems. Renew. Energ., 22: 235-239.

Swider, D.J., 2007. Compressed air energy storage in an electricity system with significant wind power generation. IEEE Trans. Energ. Convers., 22: 95-102.

Takagi, M., Y. Iwafune, H. Yamamoto, K. Yamaji, K. Okano, R. Hiwatari and T. Ikeya, 2010. Energy storage of PV using batteries of battery-switch stations. IEEE International Symposium on Industrial Electronics (ISIE 2010), pp: 3413-3419.

Ummels, B.C., M. Gibescu, E. Pelgrum, W.L. Kling and A.J. Brand, 2007. Impacts of wind power on thermal generation unit commitment and dispatch. IEEE Trans. Energ. Convers., 22: 44-51.

Yang, H.X., L. Lu and J. Burnett, 2003. Weather data and probability analysis of hybrid photovoltaicwind power generation systems in Hong Kong. Renew. Energ., 28: 1813-1824.

Ye, S.L. and B. Sun, 2009. Application of flywheel battery in solar power system. Proceeding of International Conference on Energy and Environment Technology (ICEET), 1: 533-536.

Zhang, S., K.J. Tseng, S.S. Choi, T.D. Nguyen and D.L. Yao, 2012. Advanced control of series voltage compensation to enhance wind turbine ride through. IEEE Trans. Power Electr., 27: 763-772.

Zhao, Z.Y., J.A. Zuo, L.L. Fan and G. Zillante, 2011. Impacts of renewable energy regulations on the structure of power generation in China: A critical analysis. Renew. Energ., 36: 24-30. 